\title{
Overview on Fire Detection in Japan
}

\author{
AKIO WATANABE and HIROAKI SASAKI \\ Fire Research Institute, Fire Defence Agency \\ 3-14-1, Nakahara, Mitaka, Tokyo 181, Japan
}

JUZO UNOKI

Nohmi Bosai Kogyo Co., Ltd.

4-7-3, Kudan-Minami, Chiyoda-ku, Tokyo 102, Japan

\section{ABSTRACT}

Some of unexpected fires may self-extinguish due to insufficient heat release or air supply and some may be discovered and controlled by occupants. Accordingly an automatic fire detection system plays an important role in cases where effective human detection measures couldn't be expected. In Japan, automatic fire detection systems have been obligatorily installed in buildings for specific uses having a floor space above a certain value as prescribed by the Fire Service Law. Automatic fire detection systems seem to be considerably effective but there are many cases where the bell of the control unit does not operate because the custodians of the bufldings keep the bell switched off in order to avoid false alarns. The probabilities of giving false alarm per year per detector are $6.5 \%$ in smoke detectors and $0.8 \%$ in heat detectors. There seem to be two current trends in the solution of false alarm problems. One is "right detector in the right place" and the other is to increase the information content on which discrimination between genuine fires and fire simulating phenomena can be made. Several methods have already been put into practice to greatly reduce the probability of false alarm occurrence to $1 \% /$ year.detector, and much more sophisticated fire detection systems will be adopted in near future.

\section{INTRODUCTION}

Fire detection technique has made great progress for the past 25 years, and the use of automatic fire detection systems is felt to be closer to acceptance by the general public. In Japan, the annual output of fire detectors has increased from 80,000 in 1954 to 5 million in 1984, and they have been obligatorily installed in buildings for specific uses having a floor space above a certain value as prescribed by the Fire Service Law.

At present, the reliability of detectors can be easily confirmed by various testing methods and life prediction methods. However, to pursue more effective fire detection methods, the following should be considered;

a) from ignition to extinction, there are many fire-developing stages and corresponding systems, each of which consists of many sub-systems and components and achieves the mission under different conditions, and,

b) even if the reliability of a hardware system is high, the system effectiveness will be considerably affected by the human attitude towards the system and fire. 
The present paper describes the role of human and hardware systems in fire detection and touches on the improvement of the system effectiveness.

ROLE OF HUMAN AND HARDWARE SYSTEMS IN FIRE DETECTION

Most of the unexpected fires are caused by human activities at their 1iving place. So, there may be frequently somebody near the fire origin. If he is the person Involved directly in the ignition, it's natural that he may well discover the fire first. FIGURE 1 (a) illustrates the first persons who detected the fires inside building between 1979 and 1983 in Tokyo. The figure also gives a transition probability of fire spread from "small fire" to

(a) First person who detected

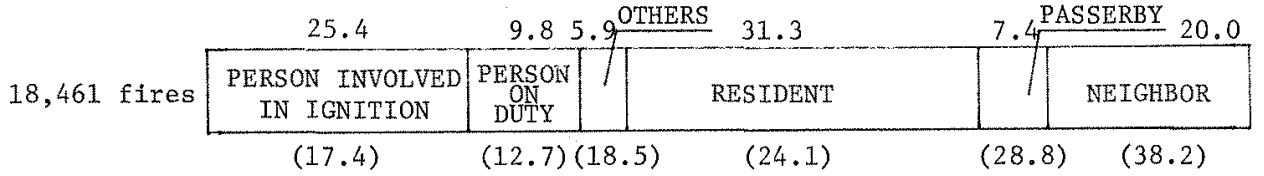

(b) Location of person who detected

\begin{tabular}{c|cc|c|c|} 
& 34.7 & 46.2 & \multicolumn{1}{c}{ SAME SITE } \\
\cline { 2 - 4 } & ROOM OF ORIGIN & BUILDING OF ORIGIN & 13.2 \\
\hline$(20.6)$ & $(20.6)$ & $(34.4)(41.3)$ \\
\hline
\end{tabular}

(c) Mode of fire detection

3,831 fires
in 1979

(d) Matter burnt when detected

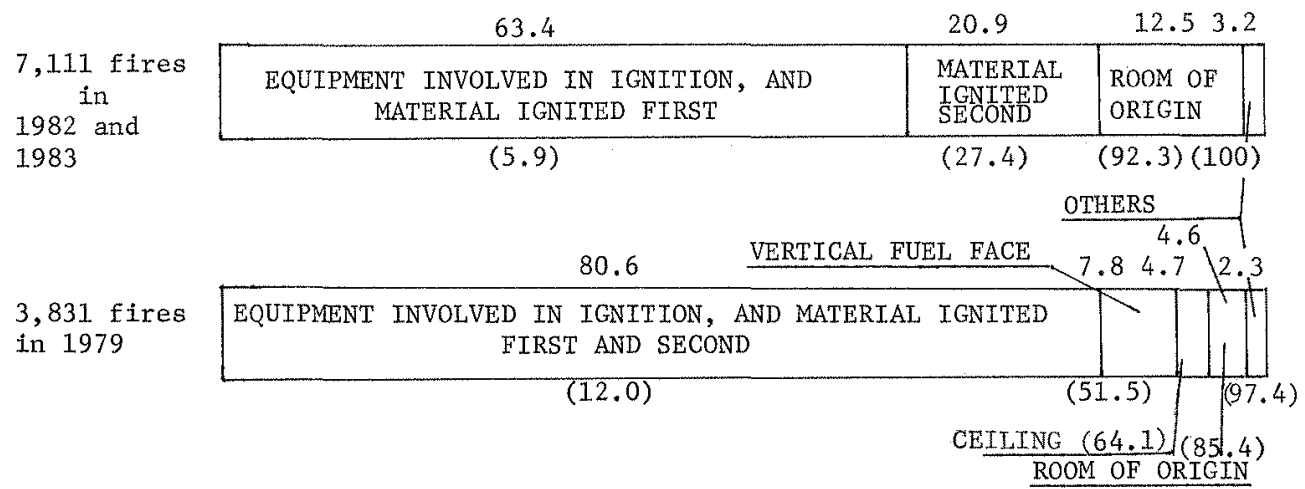

Note : Values above colume; \%

Those below colume (in parentheses); fire spread probability (\%)

FIGURE 1. Human detectors 
"partially-destroyed fire" as one of the indexes showing the effect of detection methods. In this paper, "small fire" means that the burnt floor space is below $3.3 \mathrm{sq} . \mathrm{m}$ and the ratio of fire loss to the assessed value of the building is below $10 \%$, while "partially-destroyed fire" means that the loss is over that of smal1 fire.

other questions would be where, how and when the person discovers the fire. The answers are shown in FIGURE 1 (b) - (d). From these figures, it may be concluded;

a) both fires during people's absence and the fires discovered by a guard are increased by the recent reduction of the persons on night duty in Japan,

b) lesser loss does not always link with earlier detection, and seems to depend on locating the fire spot and human activities after detection, and,

c) the largest fire spread probability is associated with detection by sound and hot air, and a relatively smaller one can be expected with automatic detection; it may be noted that detection by sme11 leads to slight damage.

After unexpected ignition, some of fires may self-extinguish due to insuificient heat release or air supply, and some may be discovered by the occupant and extinguished with his hands and feet before an automatic fire detection system operates. Statistical analysis has been done for the fires in buildings in which an automatic detection system should be installed by the law, as shown in FIGURE 2. Since fires are often controlled by occupants before the detection system operates as in FIGURE 2, the system plays an important role in cases where effective human detection measures couldn't be expected.

1 .

Undesired ignition
2.

Damage is reduced by self-extinction etc.
3.

Someone senses fire promptiy
4. By fire growth, detector operates

\section{Transition probability to partially- destroyed fire}

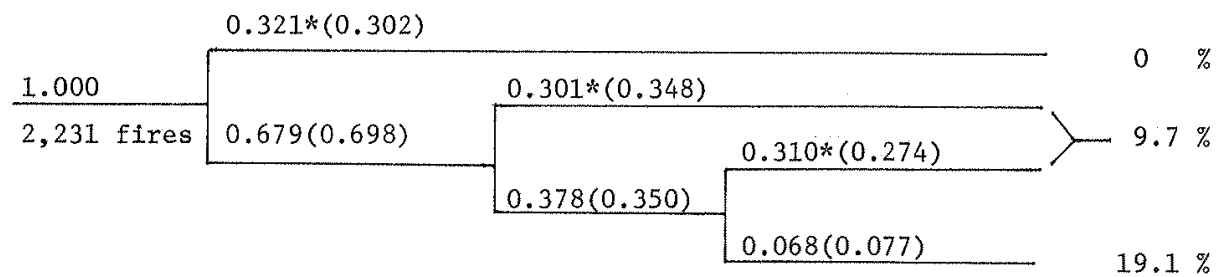

Note : * ; probability of success

Number in parentheses ; obtained by the last investigation

FIGURE 2. Probabilities of fire detection 
FIGURE 3 shows the result of the above-mentioned statistical analysis. It is seen from this figure that the fire spread probability is a little over $7 \%$ for the buildings fully protected by the automatic fire detection system and $24 \%$ for the buildings not yet equipped, that is, when the system is installed, the fire spread probability would be reduced by a factor of 3.4 as against that of non-protected buildings.

The Tokyo Fire Department have surveyed 2006 fires which occurred during 6 years from 1976 to 1981 in bulldings where automatic fire detection systems are installed. According to this report, 726 fires of the surveyed fires were detected first by the automatic fire detection systems and 797 fires were alarmed by these systems although they were detected first by human. Therefore, 1523 fires, that is, $76 \%$ of total fires were successfully detected by automatic fire detection systems. In the remainder, 309 fires, $15.4 \%$ of total fires occurred where no fire detector was installed, and 174 fires, $8.7 \%$ of total fires could not be detected by the automatic fire detection systems. $76 \%$ of these 174 unsuccessful cases happened because the bell of the control unit did not operate due to fault of management ( $56 \%$ were caused by stopping the be11 and $20 \%$ by cutting off the power supply). This fact indicates that false alarms were caused so frequently that the custodian of the building kept the bell switched off in order to avoid false alarms.

As to reliability of equipments, Japan Fire Equipment Inspection Institute made investigation on the degree of changes in function of 670 thermal and smoke detectors in operation under severe environmental condition for more than five years. According to this result a large number of detectors were found to show considerable changes in their function particularly among those installed in spa if classified by districts of their installation, and those in hotels and factories if classified by occupancies of buildings.

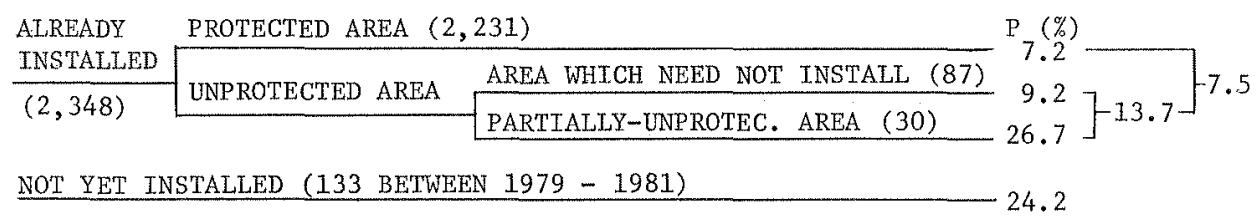

Note: Number in parentheses; the number of fires

FIGURE 3. Transition probability to partially-destroyed fire; $P$, in buildings where automatic fire detection system should be installed 
At the second half of $1960^{\prime} \mathrm{s}$, the ratios of false alarms to genuine fire alarms were $3.9: 1$ in Japan and 11.1 : 1 in England. The ratio in England was 23.8 : 1 in 1971 according to the British Fire Protection Systems Association. The reasons for world-wide increasing tendency of the ratio may be frequent use of smoke detectors for fire-safety, and the adoption of powerful air conditioning units and airtight building structures. culties.

In grasping the causes of false alarm, we meet with the following diffi-

a) it's difficult to decide on the detector giving false alarm, as plural detectors with different principles are connected in one circuit,

b) it's very rare to give false alarm at a specified place, and false alarm is frequently caused by a very quick phenomenon, and,

c) the users are apt to complain of the operation by heat or smoke produced by everyday life, as false alarm, especially in case of the obligatory installation.

The recent statistical analysis on false alarm were reported (a) on 2,787 false alarms of smoke detectors by the Association of Fire Alarm of Japan and the Tokyo Fire Alarm Maintenance Corporative Association in 1977, (b) on 553 false alarms by the Fire Equipment Safety Center of Japan, and on 7,469 false alarms in 1,500 bufldings by the Tokyo Fire Department in 1982. Although some of the results were already presented in the English language, the main findings are summarized as follows;

a) the number of false alarms, classified by month, shows the highest value between July and September.

b) the number, classified by hour, shows the highest value at 7 to $90^{\prime} \mathrm{clock}$ in the morning, and then human activities seem to affect the false alarm.

c) though half to $1 / 3$ of false alarms could't be traced to the causes, the causes mentioned were strong wind, maintenance, high humidity, artificial smoke etc. in a report, while they were cooking, smoking, exhause gases etc. In a recent report, putting the causes in order of the frequency.

d) the probabilities of giving false alarm per year per detector are summarized in TABLE 1 .

The above findings suggest that,

a) most of false alarms from smoke detectors are caused by normal combustion and heating in daily life such as smoking and cooking. False alarm of fixed temperature type detectors can be explained as they are installed under severe conditions,

b) the probabilities in the place of living and kitchen were maximum $5.6 \%$ / year-detector and $41.6 \% /$ year-detector, respectively,

c) the delay type smoke detectors could be expected to give less false alarms. 
TABLE 1. Probability (\%), of giving alarm per year.detector

\begin{tabular}{|c|c|c|c|c|c|}
\hline \multirow{4}{*}{ Alarm given by } & \multicolumn{5}{|c|}{ Probability of giving alarm per year detector $(\%)$} \\
\hline & \multicolumn{2}{|c|}{ Smoke } & \multicolumn{3}{|c|}{ Heat } \\
\hline & \multirow{2}{*}{$\begin{array}{l}\text { Ioni- } \\
\text { zation }\end{array}$} & \multirow{2}{*}{$\begin{array}{l}\text { Photo- } \\
\text { electric }\end{array}$} & \multirow{2}{*}{$\begin{array}{l}\text { Fixed } \\
\text { temp. }\end{array}$} & \multicolumn{2}{|c|}{ Rate-of-rise } \\
\hline & & & & Spot & Line \\
\hline Genuine fire & $\begin{array}{l}0.08 \\
(0)\end{array}$ & $\begin{array}{l}0.12 \\
(0)\end{array}$ & 0 & 0.06 & 0 \\
\hline $\begin{array}{l}\text { Combustion or heating } \\
\text { in daily life }\end{array}$ & $\begin{array}{l}4.36 \\
(0.47)\end{array}$ & $\begin{array}{l}0.87 \\
(0)\end{array}$ & 2.46 & 0.03 & 0 \\
\hline $\begin{array}{l}\text { Environmental factors } \\
\text { having no connection } \\
\text { with comb. or heating }\end{array}$ & $\begin{array}{c}0.63 \\
(0.23)\end{array}$ & $\begin{array}{c}0.56 \\
(0.27)\end{array}$ & 0 & 0.06 & 0 \\
\hline $\begin{array}{l}\text { Device/system defect } \\
\text { or bad maintenance }\end{array}$ & $\begin{array}{c}0.04 \\
(0.12)\end{array}$ & $\begin{array}{l}0.19 \\
(0)\end{array}$ & 0.30 & 0.06 & 0 \\
\hline Unknown cause & $\begin{array}{l}3.11 \\
(0.70)\end{array}$ & $\begin{array}{l}1.68 \\
(0)\end{array}$ & 1.49 & 0.67 & 0 \\
\hline $\begin{array}{l}\text { TOTAL EXCEPT THOSE } \\
\text { BY GENUINE FIRE }\end{array}$ & $\begin{array}{c}8.14 \\
(1.52)\end{array}$ & $\begin{array}{c}3.30 \\
(0.27)\end{array}$ & 4.25 & 0.82 & 0 \\
\hline
\end{tabular}

No. of detectors; 12,980 (Smoke ones $65.4 \%$ )

No. of false alarms; 553 (during a year)

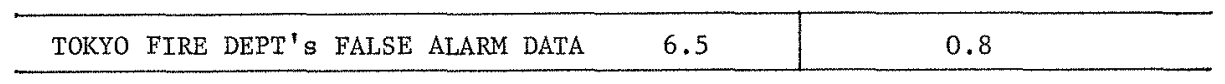

No. of detectors; 262,152 (smoke ones $37.5 \%$ )

No. of false alarms; 7.469 (during a year) 


\section{MUCH BETTER SYSTEM}

As mentioned above, there are a wide range of possible causes of false alarm. Therefore, the problem of the false alarm may be difficult to solve by a single method. There seem to be two current trends in its solutions.

One is "right detector in the right place" by using interchangeable mounting-base. This is quite a realistic solution. The other is to increase the information content as to complicated fire situations and occupants' activities. Most of the present detectors are of one-parameter and one-threshold value. They give alarm when a fire characteristics parameter exceeds the predetermined threshold value. Indeed, the fire is accompanied with heat, smoke, radiation, gas etc., but fire is not a unique source for the sensor output. Several misleading phenomena could be the source giving alarm, too. In this way it is possible for detector to give false alarm, and it is necessary to increase the information content on which discrimination between genuine fires and fire simulating phenomena is made.

Up to now, from the viewpoint of the maintenance of detectors and the signal processing, there have been proposed several methods as follows.

Adoption of multiple confirmation or integral circuit

This system checks whether the output of sensor is temporary or continuous. If the former is the case, the alarm is not given. For example, it is generally said that the use of time delay type detector is expected to decrease the false alarms by $45 \%$.

\section{Detector with individual address}

To identify the detector giving alarm, the addition of individual detector address has been proposed in recent years. The outputs of devices with ability of transmitting such an address in 1984 were about 2,000 detectors and 17,000 relaying devices having encoder. The most sophisticated system is able to remotely check the detector sensitivity; replacing the defective detectors resulted in probability of the false alarm occurrence of $0.15 \% /$ year.detector.

Sensitivity-floating detection systems

The sensitivity level is automatically set corresponding to ambient conditions such as the start of strong heating and air conditioning system.

Line type or areal type detection systems

This example is the smoke detection method measuring light-extinction over long paths. Its independence of localized heat or smoke would decrease the false alarm.

\section{Multi-stage detector} fire.

This can give several stages of alarms corresponding to the progress of 
Combined or compensation type detector

This detector is exemplified by the composite of 2 kinds of sensors so that the threshold level of smoke detector become more sensitive with temperature rise.

\section{Application of pattern recognition method}

The processes of this method are as follows.

1. Storage of data on fire characteristic values in fires and normal conditions.

2. Extraction of fire features, i.e. grasp of time variation and/or spatial distribution of fire characteristics as patterns.

3. Comparison between patterns of fire characteristic values and of measured quantity.

4. Discrimination between genuine fires and deceptive phenomena.

Thus, the system can avoid giving the false alarm. But the fire pattern is dynamic in actual fires, and so real time recognition is desirable. In this point this method is different from the ordinary pattern recognition, which is static. Citing the present examples, the pattexn recognition type fire detection systems have been developed by the Japan National Railway since the most of train fires occur in specific places such as overheat of the devices under the floor in Japan. The other relates to the visual organ of intelligent fire fighting robots.

\section{CONCLUSION}

Some of above-mentioned methods have already been put into practice to greatly reduce the probability of false alarm occurrence to $1 \% /$ year.detector. Even if the probability of individual detector is low, when more than one thousand detectors are installed in one building, the owner may suffer from false alarm. Also, iff all automatic fire detection systems in a municipality are directly connected to a fire department, the department is driven by necessity for the solution of false alarm. In these two cases, the accumulated number of false alarms in the system cannot be generously tolerable despite of the low probability.

In these years we are experiencing drastic reduction in cost of semiconductor components as well as great progress of information analysis technology, which will make it possible to adopt much more sophisticated fire detection systems as solution for the false alarm problem (cf. REFERENCE $11 \approx 17$ ).

Both pertinent human actions after detection of fire and the maintenance of the system are indispensable to effective application of the system. Therefore, the important future problem is how the system assists human beings. In other words, the goal of the system must be foolproof or fail-safe. Remembering the fire detection system is of us, by us and for us; we must get along with this honest device for our safety life.

\section{ACKNOWLEDGEMENTS}

The authors are grateful to the Tokyo Fire Department and the Fire Equipment Safety Center of Japan for their admissions of the use of the data. 


\section{REFERENCES}

1. Tokyo Fire Department : Actual Condition of Fires, 1980ed., 1981ed,, 1982ed., 1983ed. and 1984ed. (in Japanese).

2. Watanabe, A. : Effectiveness of Active Fire Protection Systems, CIB Symposium on Systems Approach to Fire Safety in Buildings (TSUKUBA), Aug. 1979.

3. Katsuno, J. : "Maintenance and Management of Fire Protection and Equipments" in Actual state of the Effectiveness of Fire Protection Facilities and Equipments, Journal of Architecture and Building Science, Vo1.98, No.1210, 1983, Architectual Institute of Japan. (in Japanese).

4. Ohkubo, I. : Outline of Follow-up Study on Detection Performance Changes with the Passage of Time in Fire Alarm Systems, Journal of Japanese Association of Fire Science and Engineering, Vol.32, N0.5, 1982. (in Japanese).

5. Gupta, Y. P. and Hart, S. J. : Some Aspects of Capability and Reliability of Automatic Fire Detection System; Second National Reliability Conference, March 1979.

6. Fry, J. F. and Eveleigh, C. : "False Alarm" in Automatic Fire Detection, FPA Journal, Oct. 1970.

7. Gomizawa, M. : False Alarm and Failed Alarm of Fire Detection Systems, Committee on Fire Alarm, Illuminating Engng. Inst: of Japan, Report No. HO-412 and 413,1968 . (in Japanese).

8. Nagata, K. : Actual Circumstances of False Alarm of Smoke of Detectors, Committee on Fire Alarm, Report No. 77-9, 1977. (in Japanese).

9. Interim Report for the Fiscal Year 1980, Research Comnittee on Fire Protection System, Fire Protec. Equipment Safety Center of Japan, June, 1981. (in Japanese).

10. Tokyo Fire Department : Investigation Findings on False Alarm of Automatic Fire Detection System, Tokyo Fire Dept. Oct. 1982. (in Japanese).

11. Takahashi, N. : Selection between Fire Alarms and Non-genuine Alarms of Ionization Smoke Sensors by $\mu$, Proceeding of Annual Meeting of Japanese Association of Fire Science and Engineering, May 1983. (in Japanese).

12. Takahashi, N, et a1. : Filtering of Ionization Smoke Sensor Output and Detection of Smoldering and Burning Fire, ibid., May 1984. (in Japanese).

13. Takahashi, N. et al. : Algortthm drawing Qualitative Information from Quantitative Output of Sensor and Result of Simulation, ibid., May 1985. (in Japanese).

14. Ono, T. et al. : Incipient Fire Pattern based on Sensor Response, ibid., May 1983. (in Japanese)

15. Ono, T. et al. : Algorithm on Judgement of Incipient Fire by Sensor Response, ibid., May 1984. (in Japanese).

16. Ono, T. et al. : Basic Research on giving Intelligence to Fire Alarm System -Frequency Response of System and Compensation for Room Figure, ibid., May 
1985. (in Japanese).

17. Takeuchi, K. and Ishii, H. : Intelligent Systems : Present Design, What they are and What they might achieve, Seminar paper reprints of IFSEC'85, London, April 1985. 